\title{
Coexisting with cheaters: Microbial exoenzyme production as a snowdrift game model
}

\author{
Constantinos Xenophontos ${ }^{1}$, Stanley Harpole ${ }^{2}$, Kirsten Kuesel ${ }^{1}$, and Adam Clark ${ }^{2}$ \\ ${ }^{1}$ Friedrich Schiller University Jena \\ ${ }^{2}$ German Centre for Integrative Biodiversity Research (iDiv) Halle-Jena-Leipzig
}

February 21, 2021

\begin{abstract}
Cheating in microbial communities is often regarded as a precursor to a "tragedy of the commons", ultimately leading to over-exploitation by a few species, and destabilisation of the community. However, this view does not explain the ubiquity of cheaters in nature. Indeed, existing evidence suggests that cheaters are not only evolutionarily and ecologically inevitable, but also play important roles in communities, like promoting cooperative behaviour. We developed a chemostat model with two microbial species and a single, complex nutrient substrate. One of the organisms, an enzyme producer, degrades the substrate, releasing an essential and limiting resource that it can use both to grow and produce more enzymes, but at a cost. The second organism, a cheater, does not produce the enzyme but benefits from the diffused resource produced by the other species, allowing it to benefit from the public good, without contributing to it. We investigated evolutionarily stable states of coexistence between the two organisms and described how enzyme production rates and resource diffusion influence organism abundances. We found that, in the long-term evolutionary scale, monocultures of the producer drive themselves extinct because selection always favours mutant invaders that invest less in enzyme production. However, the presence of a cheater buffers this runaway selection process, preventing extinction of the producer and allowing coexistence. Resource diffusion rate controls cheater growth, preventing it from outcompeting the producer. These results show that competition from cheaters can force producers to maintain adequate enzyme production to sustain both itself and the cheater. This is known in evolutionary game theory as a "snowdrift game" - a metaphor describing a snow shoveler and a cheater following in their clean tracks. We move further to show that cheating can stabilise communities and possibly be a precursor to cooperation, rather than extinction.
\end{abstract}

\section{Introduction}

Microorganisms in nature coexist in highly diverse communities. In these communities, not all species perform the same functions and therefore cooperative interactions, among others, can emerge that can benefit the whole community (Crespi, 2001; Smith and Schuster, 2019). These cooperative functions are usually extracellular, involving excreted products and metabolites that can be considered "public goods" because they can benefit the entire community. However, extracellular functions, such as complex substrate degradation (e.g., cellulose), are particularly susceptible to exploitation: i.e., cheaters benefiting from a public good without contributing to it. This is because both the means (e.g., extracellular enzymes) and the products of substrate degradation (e.g., glucose) take place outside the cell (extracellular public goods) and are therefore vulnerable to cheating. The situation where cheaters emerge to exploit a shared resource was coined the "tragedy of the commons" by Garrett Hardin (Hardin, 1968), drawing from William F. Lloyd's example of unregulated cattle grazing in a common pasture (Lloyd, 1833). This theory describes how the emergence of cheaters leads to the inevitable demise of the whole group; the cheater either takes up too many resources or the cheating behaviour propagates, leading to the same result. Cheating has been widely 
studied as a means of negative, competitive interaction between organisms and communities (Strassmann, Zhu and Queller, 2000; Velicer, Kroos and Lenski, 2000; Schusteret al. , 2017; De Leenheer, Schuster and Smith, 2019). Existing studies show that cheaters should be detrimental for the system in which they emerge, because their lower fitness costs allow them to allocate additional resources to growth and reproduction, thus outcompeting the other species. However, this situation shares similar characteristics and caveats with the competitive exclusion principle (Gause, 1934; Hardin, 1960) - regardless of reduced fitness costs, cheaters do not have the same access to the public good as producers (Letten, Ke and Fukami, 2017). Hardin's tragedy of the commons also overlooks the fact that natural biological systems are inherently reactive and, to an extent, self-regulating (Foster, 2004; Rankin, Bargum and Kokko, 2007; Ostrowski et al. , 2015). Examples of self-regulation include host policing (Oono, Anderson and Denison, 2011), the cost of selfishness (densitydependent metabolic costs create negative frequency-dependent selection (MacLean, 2008; Morris, 2015)), quorum sensing (Dandekar, Chugani and Greenberg, 2012) or kin selection in heterogeneous environments (Kreft, 2004; Mitri and Foster, 2013). Indeed, the idea that any public good will be catastrophically exploited has been heavily criticised (Dahlman, 1991; Ostrom, 1999, 2015).

Several experimental systems have shown dynamics that closely resemble a "tragedy of the commons". However, the systems continue to persist, with no runaway exploitation taking place. Such dynamics play out in predator-prey (Jones et al. , 2009; Becks et al. , 2010, 2012; Blasius et al. , 2020) and host-parasite models in chemostats (Smith and Thieme, 2012; Frickel, Sieber and Becks, 2016). The "tragedy of the commons" assumes that microbial cheating is a "prisoner's dilemma" game; coexistence only depends on both players cooperating, as otherwise cheaters overwhelm the population causing the system to collapse. Instead, given the abundance of cooperative relationships between species in communities (West et al. , 2007; Morris et al. , 2013), the interaction between producers and cheaters is more likely to be a "snowdrift" game (Smith and Schuster, 2019). The snowdrift game model is inspired by the metaphor of a snow shoveler (producer or cooperator) who pays the cost of cleaning a path in the snow, with cheaters being able to use the clean path without incurring extra costs to the shoveler (Sugden, 2005). Under these circumstances, producers will continue to invest in public goods despite exploitation by cheaters so long as they continue to obtain sufficient benefits (Gore, Youk and van Oudenaarden, 2009). The Black Queen Hypothesis (BQH) describes a similar scenario (Morris, Lenski and Zinser, 2012). The main difference between a "snowdrift" dynamic and the $\mathrm{BQH}$ is that, in a $\mathrm{BQH}$ scenario, public good producers maintain some benefits that are not available to the cheater (Mas et al. , 2016) (i.e., immediate access (Estrela, Morris and Kerr, 2016), akin to partial privatization (Pande et al. , 2015; Estrela, Morris and Kerr, 2016)). Contrastingly, in a "snowdrift" situation, the producer cedes any exclusive advantages to resolve the conflict (Smith, 1976). The BQH has been presented to describe the situation where, in planktonic microbial communities, selection promotes loss of extracellular functions involving public goods, allowing cheaters to emerge (Morris, Lenski and Zinser, 2012). This leads to a community where only a critical minimum of species perform a shared function, possibly allowing for dependencies and cooperative interactions to develop from the beneficiary species (Sachs and Hollowell, 2012; Morris, Papoulis and Lenski, 2014; Mas et al. , 2016). This raises the question of whether "snowdrift" situations are still conducive to stable coexistence.

Indeed, many studies have shown that cheaters may not only be non-destructive, but might promote biodiversity and cooperative behaviour in microbial communities (Leinweber, Fredrik Inglis and Kümmerli, 2017; Veit, 2019). In one example, wild-type

Saccharomyces cerevisiae populations produce invertase that degrades sucrose into glucose. Glucose quickly diffuses from the cells, allowing for the emergence of non-producer cheaters (Gore, Youk and van Oudenaarden, 2009). The authors showed that cheaters promoted cooperation in the experimental system by keeping glucose concentrations low, thus preventing the inhibition of invertase production. Leinweber and her collaborators have also shown that cheater mutants of Pseudomonas aeruginosa act to increase intraspecific competition, promoting coexistence with Burkholderia cenocepacia, with iron as a single limiting resource (Leinweber, Fredrik Inglis and Kümmerli, 2017). Motivated by these findings, we ask the following question: given that cheaters are ecologically and evolutionarily inevitable, how are public good producers and public good cheaters able to coexist? Based on recent findings on the ecological relevance of cheaters, we propose 
a mechanism for how cheaters might act to stabilise systems, rather than destabilising them in the classical sense. We also build on the existing literature, to show that cheaters can be crucial to the promotion and maintenance of cooperative behaviours and networks. To address our question, we develop a theoretical mixed chemostat coculture model to test for evolutionarily stable states (ESSs) of coexistence and abundance dynamics between a producer and a cheater organism provided with a single complex substrate resource. We then proceed to parameterise the model with real data, from the literature.

\section{Model description}

Our model includes two species - an enzyme producer, $N_{E}$, and a "cheater", $N_{C}$, growing in in a common environment (Figure 1). The producer species releases exoenzymes that degrade the substrate into resources that are directly used for growth and production of exoenzymes. The cheater species does not produce the exoenzyme, thereby allowing itself to allocate more resources for growth. The cheater, however, depends on the diffusion of resources from the immediate area around the producers. Within the context of our model, we wanted to test which parameters control coexistence and how similar parameter conditions influence population abundances of producer monocultures vs producer-cheater cocultures.

Other than differences in enzyme production, we assume that species share the same vital rates and requirements and that species occupy two spatially proximal, but separate patches. Specifically, population dynamics for the enzyme producer and cheater follow

$\frac{d N_{E}}{\mathrm{dt}}=\left(r R_{E}-(e+m)\right) N_{E}$ Eq. (1a)

$\frac{d N_{C}}{\mathrm{dt}}=\left(r R_{C}-m\right) N_{C}$ Eq. (1b)

where $r$ is the intrinsic growth rate, $m$ is the mortality rate, $R_{E}$ and $R_{C}$ are, respectively, resource concentration in the vicinity of the enzyme producer vs. the cheater, and $e$ describes the cost of enzyme production. Thus, the enzyme producer always has a lower per-capita growth rate at any given level of resource availability.

Enzyme production is controlled by the abundance of the enzyme producer, and follows

$\frac{\mathrm{dE}}{\mathrm{dt}}=e q_{z} N_{E}-m_{z} E$ Eq. (2)

where $q_{z}$ converts between the energetic cost of enzyme production to the producer vs. the rate of enzyme production, and $m_{z}$ describes the rate at which the enzyme breaks down over time. Note that parameter $e$ therefore jointly relates to the cost of enzyme production and the rate at which new enzyme is produced. Furthermore, in the absence of enzyme producers, all enzymes eventually break down and the concentration reduces to zero.

Resource dynamics in the model are controlled by the concentration of available substrate $S$, the concentration of enzymes that break down the substrate into usable resources, $E$, and the rates at which resources are taken up by species and diffuse between regions. We assume an open system, in which new substrate enters at a rate proportional to the current concentration, and in which resources associated with dead biomass are flushed from the system. Resource and substrate dynamics follow

$$
\begin{aligned}
& \frac{d R_{E}}{\mathrm{dt}}=\mathrm{gES}-q E_{E} r N_{E}-d R_{E}+d R_{C} \text { Eq. (3a) } \\
& \frac{d R_{C}}{\mathrm{dt}}=-d R_{C}+d R_{E}-\mathrm{qr} R_{C} N_{C} \text { Eq. (3b) } \\
& \frac{\mathrm{dS}}{\mathrm{dt}}=a\left(S_{0}-S\right)-\text { gESEq. (3c) }
\end{aligned}
$$

where $g$ describes the rate at which the enzyme breaks down the substrate, $q$ describes the quantity of resource needed to produce a biomass unit, $d$ is the diffusion rate governing movement of resource from the region around the enzyme producer to the region around the cheater, $a$ describes the rate at which 
new substrate enters the system, and $S_{0}$ is the maximal substrate concentration in the absence of enzyme producers.

At equilibrium, substrate concentration and resource concentrations in the vicinity of the enzyme producer and the cheater can be calculated as

$\begin{array}{lrrrr}R_{E}^{*}=\frac{m+e}{r} r & \text { if } & N_{E}^{*}>0, & \text { else } & R_{E}^{*}=0 \text { Eq. (4a) } \\ R_{C}^{*}=\frac{m}{r} & \text { if } & N_{C}^{*}>0, & \text { else } & R_{C}^{*}=R_{E}^{*} \text { Eq. (4b) } \\ S^{*}=\frac{a S_{0}}{m z} & \text { if } & N_{E}^{*}>0, & \text { else } & S^{*}=S_{0} \text { Eq. (4c) }\end{array}$

Because of the energetic cost of enzyme production, equilibrial resource concentrations are always higher in the vicinity of the enzyme producer. Note that these concentrations simultaneously describe the equilibrial resource concentration, and the minimum resource requirement needed for positive equilibrial abundance (Tilman, 1982), meaning that the cheater is effectively a "better" competitor than the enzyme producer, and, in the absence of the spatial gradient, would be able to drive it to extinction. Thus, if the diffusion rate is too high, the enzyme producer will ultimately be driven extinct, and the system will collapse.

Because enzyme and resource concentrations are primarily controlled by the enzyme producer, both the equilibrial enzyme concentration and the equilibrial abundance of the cheater can be described with relatively simple functions, based on the demographic rates and equilibrial concentration of the enzyme producer

$N_{C}^{*}=\frac{\text { de }}{\text { mqr }}$ Eq. (5a)

$E^{*}=\frac{e q_{z} N_{E}^{*}}{m_{z}}$ Eq. (5b)

In contrast, the equilibrial abundance of the enzyme producer, although analytically tractable, follows a more complex set of functions, which include a monoculture equilibrium value (i.e., when $N_{C}{ }^{*}=0$ ), a stable coexistence point where both $N_{E}{ }^{*}$ and $N_{C}{ }^{*}>0$, and an Allee point. If the population size of the enzyme producer falls below this Allee point and is held there long enough for resource and enzyme concentrations to equilibrate, the enzyme producer will ultimately be drawn towards extinction, because it is unable to counteract the diffusion gradient of resources being drawn towards the cheater. The full formulas for these three equilibria are available in the supplement (Table S1).

For the purpose of examining the model under realistic empirical conditions, we use parameter values reported in empirical studies. We use growth and mortality rates of Escherichia coli, a model organism in experimental microbiology and biotechnology applications. As a substrate, we identified cellulose as an appropriate carbon source. Cellulose requires specialised extracellular enzymes, cellulases, to be broken down into monosaccharides like glucose, which can be used by most bacterial species (see Table 1 for parameter values and relevant literature). For parameter $q_{z}$, a conversion term describing the relative energy cost of enzyme production vs biomass production, we chose units for $e$ such that the costs to growth are equal to enzyme production rate (i.e., $q_{z}=1$ ). Note that this choice does not change the generality of our results (other than complicating the interpretation of the units in which $e$ is measured), but rather, facilitates model testing by reducing the dimensionality of our parameter space.

Parameters $e$ and $d$ are the primary variables of interest and therefore we allow them to vary in our model, in order to find ESSs that allow for coexistence. When diffusion rate $d=0$, all resources are privatised by the producer, causing complete exclusion of the cheater. As $d$ approaches infinity it is assumed that diffusion increases (e.g., producers and cheaters are mixed in a very dense culture). Similarly, as we will show, varying $e$, the cost of enzyme production, in our model reveals maximum and minimum (non-zero) coexistence thresholds that influence both the producer monoculture and the producer-cheater mixture. 


\section{Results}

In the model, parameters $e$ and $d$ are the main drivers for coexistence. In the case of $e$, coexistence in the producer-cheater system is a product of the balance of two opposing forces; invading producer species that drive down enzyme production, and resource strain from cheaters that drives up enzyme production. These forces are at equilibrium when enzyme production investment is at the critical threshold $\left(e^{*}\right)$. As the investment in enzyme production increases in a producer-cheater mixture, the trade-offs between producer biomass and enzyme production reach a point where enzyme production requires too much energy and becomes unsustainable, causing the producer population to crash (indicated in Figure 2 with solid red vertical lines; $e=0.2067$ ). However, another threshold for enzyme production investment (where $e$ [?] 0) exists (indicated in Figure 2 with dashed vertical lines). In monoculture, selection favours producer mutants that invest less in enzyme production (i.e., with lower evalue), because these mutants can always successfully invade the producer population at equilibrium due to their higher per-capita growth rates (Figure 3A). Over time, this process reduces the production of the enzyme, which reduces the available resource, in turn reducing the population abundance of the producer. Eventually, producer abundance slowly drifts towards a critical production threshold, $e^{*}\left(e^{*}{ }_{\mathrm{m}}\right.$; Figure $\left.2 \mathrm{~A} ; e=0.0008\right)$. As investments in enzyme production drift lower thane ${ }_{\mathrm{m}}$, the total population size reaches zero abundance, going extinct and causing system collapse (Figure 3C).

In contrast, given the biologically realistic, literature-driven, parameter values we chose for the model, we observed an interesting dynamic when a cheater is present. In a producer-cheater mixture, the cheater creates a resource strain that is strong enough to prevent selection from driving producer enzyme production down to its critical limit $\left(e^{*}{ }_{\mathrm{c}}\right.$; Figure 3B; $\left.e=0.0009\right)$. This strain on resources creates a discontinuous shift in equilibrium abundance, such that below a different critical threshold, $e^{*}$, equilibrium abundance suddenly drops from positive to zero (as opposed to the slow continuous drift towards zero that occurs in producer monocultures). Moreover, in the mixed culture case where the sudden shift happens, residual resources in the system allow for the possibility of "evolutionary rescue". That is, if a new producer mutant should arise with an enzyme production rate that falls above $e^{*}{ }_{\mathrm{c}}$, it will be able to successfully invade the system, and will ultimately increase enzyme abundance sufficiently to stabilize the system (Figure 3D). In other words, the presence of a cheater allows for the possibility of long-term persistence of both strains, whereas a pure producer monoculture is doomed to relatively rapid extinction.

While resource diffusion does not exhibit the dual-threshold nature of enzyme production investment, it does control producer abundance in a producer-cheater system. As diffusion approaches higher values, producer access to its resource is impeded by the cheater, causing a population extinction and therefore a system collapse (Figure $4, d=0.152373$ ). Similarly, if diffusion is too slow (Figure $4, d=0.05$ ), the cheater's access to the resource is restricted, and the cheater population goes extinct, eventually causing the system to crash following the producer-only evolutionary dynamics described above. Importantly, for the range of biologically realistic model parameters that we consider here, cheaters cannot overgrow the producers.

\section{Discussion}

Due to their important role in theoretical and experimental microbial ecology, cheaters have been widely studied in multiple systems. While in many cases, cheating is considered an eco-evolutionary prisoner's dilemma, many have provided evidence that at least in some instances, cheating leads to coexistence as a result of a snowdrift game. We expand on the previous literature by showing that cheating not only promotes coexistence but that it also encourages the maintenance of cooperative behaviours, such as the production of extracellular public goods. Moreover, since cheaters are ecologically and evolutionarily inevitable, while cooperative behaviours continue to persist in microbial communities, we focused on ESSs of coexistence in a producer-cheater system. Thus, we developed a model showing that the interaction between a producer and a cheater influences the production and maintenance of a public good. Using experimental data to parameterise 
our model, we observed a dichotomy between scenarios of a producer monoculture and a producer-cheater mixed culture, in the context of enzyme production evolution. In the producer monoculture, a population with a set enzyme investment is always invadable by producer mutants that invest less energy in enzyme production. This trend of ever-decreasing enzyme production for short-terms growth benefits eventually causes the population to drift to extinction. In nature, we assume that public good producer populations are driven by selection towards a lower production of the public good, as a result of intraspecific competition (Morris, Lenski and Zinser, 2012; Sachs and Hollowell, 2012; Lindsay, Pawlowska and Gudelj, 2019). We propose that the ESS- $e{ }_{m}^{*}$ effect in the producer monoculture, imposed on the enzyme producer's abundance (Figure 2B), would not result in extinction in nature if the public good is crucial for survival and has no alternatives. Under these circumstances, the population will eventually have to diverge into coexisting "wildtype" and cheater "mutant" subpopulations because the persistence of the "wild-type" producer is necessary for the survival of both subpopulations. Divergence due to intraspecific competition has been a widely studied (Rosenzweig et al. , 1994; Travisano, Vasi and Lenski, 1995; Lenski et al. , 1998; Rainey and Travisano, 1998; MacLean, Dickson and Bell, 2005; Cooper and Lenski, 2010). Indeed, a cheater like the one we use in our model would have likely emerged as the product of speciation due to a similarly critical threshold of an eco-evolutionary process caused the producer population to bifurcate. Importantly, our results show that in the case of the producer-cheater mixture, cheating might strengthen intraspecific competition, thereby leading to conditions where selection favours higher enzyme production. In our simulations, the ultimate result is an increase in the long-term persistence of the system when cheaters are present. Interspecific competition has also been shown to inhibit further adaptive population radiation, such as the emergence of lower $e$ producer invaders in our model, by elimination the ecological opportunity for further adaptive radiation (Bailey et al. , 2013). In our model, we simulate population divergence with the rescue scenario (Figure 2D).

Such cheater-producer dynamics can either be between strains of the same species or different species. In the planktonic communities of a BQH scenario, adaptive gene loss and production of a vital public good in the microbial community are at equilibrium. Producers keep up the public good production because a reduction in public good concentration would negatively affect the entire community, including themselves. Producers also persist in the community, despite the cheaters, due to advantages inherent to the production of the public good and other cooperative interactions. For example, cheaters of one public good might be cooperators for a different function (Morris, Lenski and Zinser, 2012; Sachs and Hollowell, 2012). Cheaters could then be diverting resource, saved on one side of the metabolic scale, to the production of another public good. This would expand the interaction horizon, from cheating, to commensalism (Morris, Lenski and Zinser, 2012). Indeed, the presence of more than 1-way interactions (like cheating) in natural communities could help support the vast biodiversity we observe in nature (Bairey, Kelsic and Kishony, 2016). Multicellularity is perhaps the most profound example of microbial cooperation. The evolution of multicellularity may also be holding some clues as to the ecological role of cheaters (Rainey and Kerr, 2010; Hammerschmidt et al. , 2014; (as cited in Veit, 2019)). Indeed, cheaters might have had a role in the emergence of multicellularity for similar reasons as to those that we explore here.

Hardin's 1968 paper has been influencing ecological theory and research ever since, despite the efforts of critics. While most of the academic literature has move on from the "tragedy of the commons", the idea continues to influence human economics, politics and policymaking (Maldonado and Moreno-Sanchez, 2016; Mattke et al. , 2017; Gross and De Dreu, 2019). The industrial revolution has changed the world from a zero-sum game to a positive sum game (Clark, 2014) - resources could be created by increased productivity instead of at the expense of others. But since this is a very recent development in human history, the consequences are not intuitive. Being a cooperator frees up the beneficiaries (so-called "cheaters") to invest more in their own development and eventually returning the benefit in another form (different public good), like in the extension of the BQ scenario. In that sense, "snowdrift" games might be the first step towards complex cooperative communities. Santos and colleagues modelled diverse human social networks (Santos, Santos and Pacheco, 2008). Like in our model, cheaters orchestrate their own demise when they take over a network. Additionally, due to the negative frequency selection brought by the increasing numbers of cheaters, 
they become more vulnerable to producer invasions. Successfully invaded networks remain cooperative. They move on to suggest that the act of cooperation is more important than the cost it incurs to the producers.

Looking ahead, our model can be modified to be a closed system where dead cells $(m)$, denatured enzymes $\left(m_{z}\right)$ are recycled back into the substrate pool $(S)$ and an outflow parameter $\left(a_{z}\right)$ is included to maintain parameter concentrations, much like a real chemostat. Heterogeneous, spatially structured environments have been shown to prevent (Hauert and Doebeli, 2004) or promote (Santos, Pacheco and Lenaerts, 2006) the emergence of cooperative interactions, depending on parameters such as dynamic formation/severance of links between individuals. Adding an environmental structure parameter to the model, could inform about differences in cheating-altruism dynamics between spatially distinct environments, such as homogeneous groundwater and heterogeneous soil.

The complexity of natural ecosystems means that it is extremely difficult to study, experimentally and computationally. While care should be taken as to not fall in the trap of simplistic explanations for species interactions, under the enticement of intuitive conclusions, simplified systems are excellent for the mechanistic understanding of processes. Ultimately, understanding how organisms like microbes are linked to each other with more than one-way interactions can help us develop better approaches to deal with issues in medicine, environmental management and human socioeconomics.

\section{Data Accessibility}

On publication, the $\mathrm{R}$ code for the producer-cheater coexistence model used in this study will be available on GitHub and in the Dryad Digital Depository.

\section{Competing interests}

The authors have no conflicts of interest to declare.

\section{Acknowledgements and Funding}

We gratefully acknowledge the support of the German Centre for Integrative Biodiversity Research (iDiv) Halle-Jena-Leipzig funded by the Deutsche Forschungsgemeinschaft (DFG, German Research Foundation) (DFG FZT 118, 202548816). This project has been conducted in the framework of the iDiv-Flexpool - the internal funding mechanism of iDiv.

\section{Author Contributions}

WSH and KK secured funding for the project. CX, ATC, and WSH designed the study and conceptualised the model. CX collected literature biological data. ATC scripted the code for the model. All co-authors assisted in interpreting the results; CX initiated the manuscript writing, which was finalized with substantial contributions from ATC, SWH and KK

\section{References}

Bailey, S. F., Dettman, J. R., Rainey, P. B. and Kassen, R. (2013) "Competition both drives and impedes diversification in a model adaptive radiation," Proceedings. Biological sciences / The Royal Society , 280(20131253). doi: 10.1098/rspb.2013.1253. 
Bairey, E., Kelsic, E. D. and Kishony, R. (2016) "High-order species interactions shape ecosystem diversity," Nature communications . Nature Publishing Group, 7(12285). doi: 10.1038/ncomms12285.

Becks, L., Ellner, S. P., Jones, L. E. and Hairston, N. G. J. (2010) "Reduction of adaptive genetic diversity radically alters eco-evolutionary community dynamics," Ecology letters , 13(8), pp. 989-997. doi: 10.1111/j.1461-0248.2010.01490.x.

Becks, L., Ellner, S. P., Jones, L. E. and Hairston, N. G. J. (2012) "The functional genomics of an ecoevolutionary feedback loop: Linking gene expression, trait evolution, and community dynamics," Ecology letters , 15(5), pp. 492-501. doi: 10.1111/j.1461-0248.2012.01763.x.

Blasius, B., Rudolf, L., Weithoff, G., Gaedke, U. and Fussmann, G. F. (2020) "Long-term cyclic persistence in an experimental predator-prey system," Nature , 577(7789), pp. 226-230. doi: 10.1038/s41586-019-1857-0.

Clark, G. (2014) "Chapter 5 - The Industrial Revolution," in Aghion, P. and Durlauf, S. N. (eds.) Handbook of Economic Growth . Elsevier, pp. 217-262. doi: 10.1016/B978-0-444-53538-2.00005-8.

Cooper, T. F. and Lenski, R. E. (2010) "Experimental evolution with E. coli in diverse resource environments. I. Fluctuating environments promote divergence of replicate populations," BMC evolutionary biology , 10, p. 11. doi: $10.1186 / 1471-2148-10-11$.

Crespi, B. J. (2001) "The evolution of social behavior in microorganisms," Trends in ecology $E$ evolution , 16(4), pp. 178-183. doi: 10.1016/s0169-5347(01)02115-2.

Dahlman, C. J. (1991) "The tragedy of the commons that wasn't: On technical solutions to the institutions game," Population and environment, 12(3), pp. 285-296. doi: 10.1007/BF01357919.

Dandekar, A. A., Chugani, S. and Greenberg, E. P. (2012) "Bacterial quorum sensing and metabolic incentives to cooperate," Science, 338(6104), pp. 264-266. doi: 10.1126/science.1227289.

De Leenheer, P., Schuster, M. and Smith, H. (2019) "Strong cooperation or tragedy of the commons in the chemostat," Mathematical biosciences and engineering: MBE , 16(1), pp. 139-149. doi: $10.3934 /$ mbe.2019007.

Estrela, S., Morris, J. J. and Kerr, B. (2016) "Private benefits and metabolic conflicts shape the emergence of microbial interdependencies," Environmental microbiology , 18(5), pp. 1415-1427. doi: 10.1111/14622920.13028.

Foster, K. R. (2004) "Diminishing returns in social evolution: the not-so-tragic commons," Journal of evolutionary biology , 17(5), pp. 1058-1072. doi: 10.1111/j.1420-9101.2004.00747.x.

Frickel, J., Sieber, M. and Becks, L. (2016) "Eco-evolutionary dynamics in a coevolving host-virus system," Ecology letters , 19(4), pp. 450-459. doi: 10.1111/ele.12580.

Gause, G. F. (1934) The Struggle for Existence. Williams \& Wilkins, p. 163. Available at: https://insights.ovid.com/crossref?an=00010694-193602000-00018.

Gore, J., Youk, H. and van Oudenaarden, A. (2009) "Snowdrift game dynamics and facultative cheating in yeast," Nature , 459(7244), pp. 253-256. doi: 10.1038/nature07921.

Gross, J. and De Dreu, C. K. W. (2019) "Individual solutions to shared problems create a modern tragedy of the commons," Science advances , 5(4), p. eaau7296. doi: 10.1126/sciadv.aau7296.

Hammerschmidt, K., Rose, C. J., Kerr, B. and Rainey, P. B. (2014) "Life cycles, fitness decoupling and the evolution of multicellularity," Nature . Nature Publishing Group, 515(7525), pp. 75-79. doi: 10.1038/nature13884.

Hardin, G. (1960) "The competitive exclusion principle," Science , pp. 1292-1297. doi: 10.1126/science.131.3409.1292. 
Hardin, G. (1968) "The tragedy of the commons," Science, 162(3859), pp. 1243-1248. doi: 10.1126/science.162.3859.1243.

Hauert, C. and Doebeli, M. (2004) "Spatial structure often inhibits the evolution of cooperation in the snowdrift game," Nature , 428(6983), pp. 643-646. doi: 10.1038/nature02360.

Jones, L. E., Becks, L., Ellner, S. P., Hairston, N. G., Yoshida, T. and Fussmann, G. F. (2009) "Rapid contemporary evolution and clonal food web dynamics," Philosophical transactions of the Royal Society of London. Series B, Biological sciences, 364(1523), pp. 1579-1591. doi: 10.1098/rstb.2009.0004.

Kreft, J.-U. (2004) "Biofilms promote altruism," Microbiology , 150(Pt 8), pp. 2751-2760. doi: 10.1099/mic.0.26829-0.

Leinweber, A., Fredrik Inglis, R. and Kummerli, R. (2017) "Cheating fosters species co-existence in wellmixed bacterial communities," The ISME journal , 11(5), pp. 1179-1188. doi: 10.1038/ismej.2016.195.

Lenski, R. E., Mongold, J. A., Sniegowski, P. D., Travisano, M., Vasi, F., Gerrish, P. J. and Schmidt, T. M. (1998) "Evolution of competitive fitness in experimental populations of E. coli: what makes one genotype a better competitor than another?," Antonie van Leeuwenhoek , 73(1), pp. 35-47. doi: 10.1023/a:1000675521611.

Letten, A. D., Ke, P.-J. and Fukami, T. (2017) "Linking modern coexistence theory and contemporary niche theory," Ecological monographs , 87(2), pp. 161-177. doi: 10.1002/ecm.1242.

Lindsay, R. J., Pawlowska, B. J. and Gudelj, I. (2019) "Privatization of public goods can cause population decline," Nature ecology \& evolution . Springer US, 3(8), pp. 1206-1216. doi: 10.1038/s41559-019-0944-9.

Lloyd, W. F. (1833) Two Lectures on the Checks to Population . Oxford University Press. doi: $10.2307 / 1972412$.

MacLean, R. C. (2008) "The tragedy of the commons in microbial populations: insights from theoretical, comparative and experimental studies," Heredity , 100(5), pp. 471-477. doi: 10.1038/sj.hdy.6801073x.

MacLean, R. C., Dickson, A. and Bell, G. (2005) "Resource competition and adaptive radiation in a microbial microcosm," Ecology letters , 8(1), pp. 38-46. doi: 10.1111/j.1461-0248.2004.00689.x.

Maldonado, J. H. and Moreno-Sanchez, R. D. P. (2016) "Exacerbating the Tragedy of the Commons: Private Inefficient Outcomes and Peer Effect in Experimental Games with Fishing Communities," PloS one, 11(2), p. e0148403. doi: 10.1371/journal.pone.0148403.

Mas, A., Jamshidi, S., Lagadeuc, Y., Eveillard, D. and Vandenkoornhuyse, P. (2016) "Beyond the Black Queen Hypothesis," The ISME journal . Nature Publishing Group, 10(9), pp. 1-7. doi: 10.1038/ismej.2016.22.

Mattke, S., Liu, H., Hoch, E. and Mulcahy, A. W. (2017) "Avoiding the Tragedy of the Commons in Health Care: Policy Options for Covering High-Cost Cures," Rand health quarterly , 6(2), p. 1. Available at: https://www.ncbi.nlm.nih.gov/pubmed/28845339.

Mitri, S. and Foster, K. R. (2013) "The genotypic view of social interactions in microbial communities," Annual review of genetics , 47, pp. 247-273. doi: 10.1146/annurev-genet-111212-133307.

Morris, B. E. L., Henneberger, R., Huber, H. and Moissl-Eichinger, C. (2013) "Microbial syntrophy: Interaction for the common good," FEMS microbiology reviews , 37(3), pp. 384-406. doi: 10.1111/1574-6976.12019.

Morris, J. J. (2015) "Black Queen evolution: The role of leakiness in structuring microbial communities," Trends in genetics: TIG . Elsevier Ltd, 31(8), pp. 475-482. doi: 10.1016/j.tig.2015.05.004.

Morris, J. J., Lenski, R. E. and Zinser, E. R. (2012) "The Black Queen Hypothesis: Evolution of Dependencies through Adaptive Gene Loss," mBio , 3(2), pp. 1-7. doi: 10.1128/mBio.00036-12. 
Morris, J. J., Papoulis, S. E. and Lenski, R. E. (2014) "Coexistence of evolving bacteria stabilized by a shared Black Queen function," Evolution; international journal of organic evolution , 68(10), pp. 2960-2971. doi: 10.1111/evo.12485.

Oono, R., Anderson, C. G. and Denison, R. F. (2011) "Failure to fix nitrogen by non-reproductive symbiotic rhizobia triggers host sanctions that reduce fitness of their reproductive clonemates," Proceedings. Biological sciences / The Royal Society, 278(1718), pp. 2698-2703. doi: 10.1098/rspb.2010.2193.

Ostrom, E. (1999) "COPING WITH TRAGEDIES OF THE COMMONS," Annual Review of Political Science. Annual Reviews, 2(1), pp. 493-535. doi: 10.1146/annurev.polisci.2.1.493.

Ostrom, E. (2015) Governing the Commons: The Evolution of Institutions for Collective Action . Cambridge University Press. doi: 10.1017/CBO9781316423936.

Ostrowski, E. A., Shen, Y., Tian, X., Sucgang, R., Jiang, H., Qu, J., Katoh-Kurasawa, M., Brock, D. A., Dinh, C., Lara-Garduno, F., Lee, S. L., Kovar, C. L., Dinh, H. H., Korchina, V., Jackson, L., Patil, S., Han, Y., Chaboub, L., Shaulsky, G., Muzny, D. M., Worley, K. C., Gibbs, R. A., Richards, S., Kuspa, A., Strassmann, J. E. and Queller, D. C. (2015) "Genomic signatures of cooperation and conflict in the social amoeba," Current biology: CB , 25(12), pp. 1661-1665. doi: 10.1016/j.cub.2015.04.059.

Pande, S., Kaftan, F., Lang, S., Svatos, A., Germerodt, S. and Kost, C. (2015) "Privatization of cooperative benefits stabilizes mutualistic cross-feeding interactions in spatially structured environments," The ISME journal , pp. 1-11. doi: 10.1038/ismej.2015.212.

Rainey, P. B. and Kerr, B. (2010) "Cheats as first propagules: a new hypothesis for the evolution of individuality during the transition from single cells to multicellularity," BioEssays: news and reviews in molecular, cellular and developmental biology , 32(10), pp. 872-880. doi: 10.1002/bies.201000039.

Rainey, P. B. and Travisano, M. (1998) "Adaptive radiation in a heterogeneous environment," Nature , 394(6688), pp. 69-72. doi: 10.1038/27900.

Rankin, D. J., Bargum, K. and Kokko, H. (2007) "The tragedy of the commons in evolutionary biology," Trends in ecology $\mathcal{E}$ evolution, 22(12), pp. 643-651. doi: 10.1016/j.tree.2007.07.009.

Rosenzweig, R. F., Sharp, R. R., Treves, D. S. and Adams, J. (1994) "Microbial evolution in a simple unstructured environment: genetic differentiation in Escherichia coli," Genetics , 137(4), pp. 903-917. Available at: https://www.ncbi.nlm.nih.gov/pubmed/7982572.

Sachs, J. L. and Hollowell, A. C. (2012) "The Origins of Cooperative Bacterial Communities," mBio , 3(3), pp. 1-3. doi: 10.1128/mBio.00099-12.

Santos, F. C., Pacheco, J. M. and Lenaerts, T. (2006) "Evolutionary dynamics of social dilemmas in structured heterogeneous populations," Proceedings of the National Academy of Sciences of the United States of America , 103(9), pp. 3490-3494. doi: 10.1073/pnas.0508201103.

Santos, F. C., Santos, M. D. and Pacheco, J. M. (2008) "Social diversity promotes the emergence of cooperation in public goods games," Nature , 454(7201), pp. 213-216. doi: 10.1038/nature06940.

Schuster, M., Foxall, E., Finch, D., Smith, H. and De Leenheer, P. (2017) "Tragedy of the commons in the chemostat," PloS one, 12(12), p. e0186119. doi: 10.1371/journal.pone.0186119.

Smith, H. L. and Thieme, H. R. (2012) "Persistence of bacteria and phages in a chemostat," Journal of mathematical biology , 64(6), pp. 951-979. doi: 10.1007/s00285-011-0434-4.

Smith, J. M. (1976) "Evolution and the Theory of Games: In situations characterized by conflict of interest, the best strategy to adopt depends on what others are doing," American scientist. Sigma Xi, The Scientific Research Society, 64(1), pp. 41-45. Available at: http://www.jstor.org/stable/27847040. 
Smith, P. and Schuster, M. (2019) "Public goods and cheating in microbes," Current biology: CB , 29(11), pp. R442-R447. doi: 10.1016/j.cub.2019.03.001.

Strassmann, J. E., Zhu, Y. and Queller, D. C. (2000) "Altruism and social cheating in the social amoeba Dictyostelium discoideum," Nature , 408(6815), pp. 965-967. doi: 10.1038/35050087.

Sugden, R. (2005) The Economics of Rights, Co-operation and Welfare . Palgrave Macmillan, London. doi: $10.1057 / 9780230536791$.

Tilman, D. (1982) Resource competition and community structure, pp. 1-296. Available at: https://www.ncbi.nlm.nih.gov/pubmed/7162524.

Travisano, M., Vasi, F. and Lenski, R. E. (1995) "Long-term experimental evolution in Escherichia coli. III. Variation among replicate populations in correlated responses to novel environments," Evolution; international journal of organic evolution , 49(1), pp. 189-200. doi: 10.1111/j.1558-5646.1995.tb05970.x.

Veit, W. (2019) "Evolution of multicellularity: cheating done right," Biology $\&$ philosophy . Springer Netherlands, 34(3), p. 34. doi: 10.1007/s10539-019-9688-9.

Velicer, G. J., Kroos, L. and Lenski, R. E. (2000) "Developmental cheating in the social bacterium Myxococcus xanthus," Nature , 404(6778), pp. 598-601. doi: 10.1038/35007066.

West, S. A., Diggle, S. P., Buckling, A., Gardner, A. and Griffin, A. S. (2007) "The Social Lives of Microbes," Annual review of ecology, evolution, and systematics . Annual Reviews, 38(1), pp. 53-77. doi: 10.1146/annurev.ecolsys.38.091206.095740.

\section{Term definitions}

\begin{tabular}{lll}
\hline Term & Description & Reference \\
\hline Public good & An extracellular product or & (Smith and Schuster, 2019) \\
& function that benefits all & \\
& community members. Also known & \\
& as common pool resource. & \\
& Examples: Exoenzymes, & \\
& antibiotics, siderophores & \\
& Selective gene loss of costly public & (Morris, Lenski and Zinser, 2012) \\
& good functions. Example: & \\
Black Queen Hypothesis & Production of extracellular & \\
& catalase-peroxidases in & \\
& cyanobacteria communities. & \\
& Game theory scenario where & (Sugden, 2005; Gore, Youk and \\
& cheating and cooperation produce & van Oudenaarden, 2009) \\
Snowdrift & win-compromise situations. Also & \\
& known as "Chicken" or & \\
& "Hawk-Dove" games. & (Sugden, 2005; Schuster et al., \\
Game theory scenario where & 2017) \\
& win-lose situations are more & \\
& beneficial to the cheater than & \\
& cooperation. &
\end{tabular}




\begin{tabular}{lll}
\hline Term & Description & Reference \\
\hline Tragedy of the commons & Catastrophic exploitation of a & (Hardin, 1968) \\
& common resource, leading to & \\
& extinction or producers and & \\
& cheaters. \\
\hline
\end{tabular}

\section{Figure Legends}

\section{Figure 1}

Schematic of a chemostat model with producer and cheater populations and a single complex substrate resource. Variables: $N_{E}=$ enzyme producer population; $N_{C}=$ cheater population, $S=$ substrate; $E=$ enzyme; $R_{E}=$ enzyme producer resource; $N_{C}=$ cheater resource. Parameters: $a=$ substrate inflow rate; $g=$ rate of substrate degradation by enzymes; $e=$ enzyme production investment by the producer; $d=$ resource diffusion rate; $q=$ quantity of resource required for the production of species biomass; $r=$ species growth rate; $m=$ species mortality rate.

\section{Figure 2}

Effect of parameter $e$ on species abundances and coexistence. The dash-dotted red vertical line marked $e^{*}$ indicates a criticale value creating an EES for the producer, in the context of enzyme production investment $\left(e^{*}{ }_{\mathrm{m}}=0.0009\right)$. Solid red vertical lines marked $e^{\circ}$ show the maximum e value before the enzyme producer population collapses due to the increased investment in enzyme production $(e=0.2067)$. In (A) we show the effect of the $e^{*}$ on the abundance of the enzyme producer as a monoculture (blue) and in a mixture (gold). Due to the invasibility of the producer monoculture by producers with lower $e$, producer abundance can eventually drift to zero. On the other hand, the presence of the cheater in the same situation creates a discontinuous shift from a positive to a negative equilibrium $\left(e{ }_{\mathrm{c}}=0.0008\right)$, preventing any further invasion of lower $e$ producers. Since cheater abundance (B), resource release (C, D) and enzyme (E) and substrate (F) concentrations are tightly linked to producer abundance, they follow similar dynamics in producer-cheater mixtures. In the absence of a producer, substrate concentration returns to baseline, indicated by the dotted black horizontal line in (F) Due to the plotting scale $e{ }_{\mathrm{m}}$ and $e{ }^{*}{ }_{\mathrm{c}}$ are overlapping and are both shown with the single $e^{*}$ dash-dotted red vertical line.

\section{Figure 3}

(A) Here we show the invasion rate of producers with variations in their investment in enzyme production. Producers who invest less in enzyme production have higher invasion rates and success. At the $e$ for which the invasion success intersects with zero invasion rate, an ESS of the producer population emerges $\left(e^{*}=0.0009\right)$.

(B) Effects of model parameter $e$ on the abundance of the enzyme producer. The solid red vertical line signifies the maximum e before negative growth occurs $(\max e=0.2067)$ due to allocating too many resources into enzyme production and not growth. The dash-dotted red vertical line indicates the lowest possible $e$, a critical enzyme production investment threshold, allowed in the model before negative growth occurs for the enzyme producer, due to lack of resource release from the substrate $\left(e^{*}=0.0009\right)$. This enzyme production investment threshold creates an uninvadable ESS - producers with lower enzyme production investment can no longer invade the producer population due to the presence of the cheater.

(C-D) Show the effect of lowering the cost of enzyme production belowe ${ }^{*}$. This change causes a discontinuous shift in equilibrial abundance for the enzyme producer, driving it towards extinction because it is no longer able to produce enough resources to overcome the diffusion gradient towards the cheater. If the cost of 
enzyme production remains below the threshold value, the enzyme producer is ultimately driven extinct (C). If the cost of enzyme production is increased back above the threshold value before resources are depleted, the enzyme producer is able to recover (D). This is possible due to residual resources in the system, allowing the producer population to recover. In our model, the producer cannot be rescued if its abundance crosses below the shaded red area. Parameters: $a=0.01 ; g=72.64 ; d=0.10 ; q=0.65 ; m_{z}=1.05 ; r=2.08 ; m$ $=0.11$.

\section{Figure 4}

Similar to Figure 3, the effect of resource diffusion rate, parameterd, on species abundances and coexistence is shown (A). Increasing diffusion rate in the producer-cheater mixture (golden line in (A)) reduces resource availability to the producer, leading to extinction and system collapse. Since cheater abundance (B), resource release $(\mathrm{C}, \mathrm{D})$ and enzyme (E) and substrate $(\mathrm{F})$ concentrations are tightly linked to producer abundance, the follow the trajectory of producer abundance, in producer-cheater mixtures. In the absence of a producer, substrate concentration returns to baseline, indicated by the dotted black horizontal line in $(\mathrm{F})$.

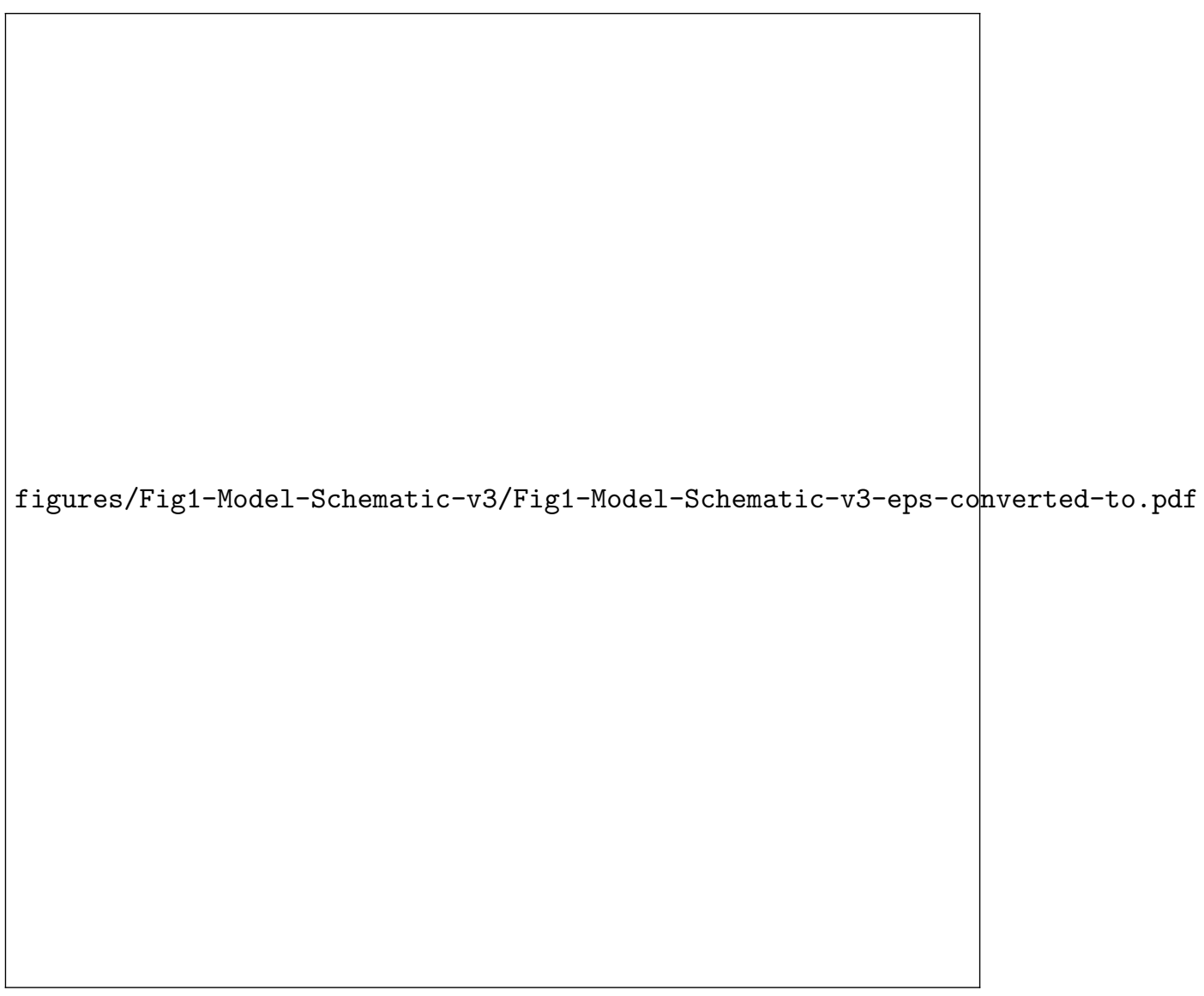


figures/Fig2-e-plots/Fig2-e-plots-eps-converted-to.pdf 
figures/Fig3-e-effect-plots/Fig3-e-effect-plots-eps-converted-to.pdf 
figures/Fig4-d-plots/Fig4-d-plots-eps-converted-to.pdf 